\title{
STUDY OF THE LIGHTNING IMPACT ON THE WIND-TURBINE
}

\author{
${ }^{1}$ Dib Djalel, ${ }^{1}$ Guebla Abdallah and ${ }^{2}$ Labar Hocine \\ ${ }^{1}$ Department of Electrical Engineering, Laboratory of Electrical Engineering LABGET, \\ University of Tebessa-12002-Tebessa, Algeria \\ ${ }^{2}$ Department of Electrical Engineering, University of Annaba Sidi Ammar, Annaba, Annaba, Algeria
}

Received 2012-07-30; Revised 2014-07-28; Accepted 2014-08-12

\begin{abstract}
Generally, lightning damage has mainly been to home appliances and telephones, Towers and power transmission and generation equipment mal functions and damage due to strikes on power lines. With the adoption of wind power generation equipment, however, lightning damage is also increasing in this area. Through his dimensional characteristics and the wind power system is more exposed in the nature of all others. Lightning damage is the single largest cause of unplanned downtime in wind turbines and that downtime is responsible for the loss of countless megawatts of power generation. Wind turbines are high structures and, like tall towers, they not only attract downward flashes but initiate upward flashes as well. The rotation of the blades may also trigger lightning and result in considerable increase in the number of strikes to a wind turbine unit. Since wind turbines are tall structures, the lightning currents that are injected by return strokes into the turbines will be affected by reflections at the top, at the bottom and at the junction of the blades with the static base of the turbine. We present in this study our contribution to study of the impact of direct and indirect lightning strokes on wind turbines.
\end{abstract}

Keywords: Wind Turbine, Lightning, Protection, Blade, Current Return Stroke, Carbon Reinforced Plastics

\section{INTRODUCTION}

Wind energy is one of the fastest growing electric power generation technologies and the lightning strokes are a wind turbine's worst enemy! Due to their height of over $100 \mathrm{~m}$ and location mostly in remote areas, wind turbines are exposed to lightning strokes up to 10 times a year. In the 1990 s that quite often caused heavy damages. In 1995 approx 80\% of the damages registered by insurances were caused by lightning (Arboleda, 2003).

It is well known that wind turbines are vulnerable to lightning, which can cause important damages to wind turbine components. Currently available statistics reveal that for the wind turbines installed in Europe, the average number of faults per 100 turbine years is equal to six, whereas for the wind turbines installed in a European country like Sweden or Japan as Asian leader in the extraction of electricity from Wind Turbines, this value can reach even 36 due to the severe winter lightning parameters.

However, modern wind power generation units are characterized by ever taller turbines and wind turbine blades are now being produced with lengths of $60 \mathrm{~m}$ and beyond. Since insurance companies demand for proper lightning defense, lightning has nowadays lost its terrifying effect for the users. Even retrofitted turbines withstand lightning strokes without serious problems.

According to statistics annually only 4-8\% of modern European wind turbines get damages induced by lightning. The majority of the faults are caused in the control device, the generator and on the blades.

Corresponding Author: Dib Djalel, Department of Electrical Engineering, Laboratory of Electrical Engineering LABGET, University of Tebessa-12002-Tebessa, Algeria 
Wind turbines have the specialty that the blades and the nacelle rotate and change position during their function. Significant parts of lightning current (Baba and Rakov, 2005) passes through or near to all wind turbine components and also passes electronic equipments, which contain control or measuring devices.

The most vulnerable parts of the turbine for direct lightning strokes are the blades, the tower itself, the hub, the frame of the nacelle and the lightning receptors on top of the nacelle.

Most likely is the direct hit into the rotor blades. Depending on the direction and kind of the lightning stroke the current is between 20.000 Amperes and 300.000 Amperes.

The observed current is estimated by the sum of Consequently, the design of lightning protection of modern wind turbines will be a challenging problem. In this paper, we discuss the salient issues related to lightning protection of long wind turbine blades. We present the theoretical and empirical approaches to evaluate lightning incidence to tall structures (Pavanello et al., 2007), with special emphasis on upward-initiated lightning flashes, which are predominant for tall structures (Fig. 1).

The interaction of lightning with tall structures, such as telecommunication towers, has recently attracted considerable attention of lightning researchers. It has been shown in particular that the lightning current along a tall structure exhibits multiple reflections occurring at the discontinuities and resulting in a no uniform distribution of the current (Berger, 1972).

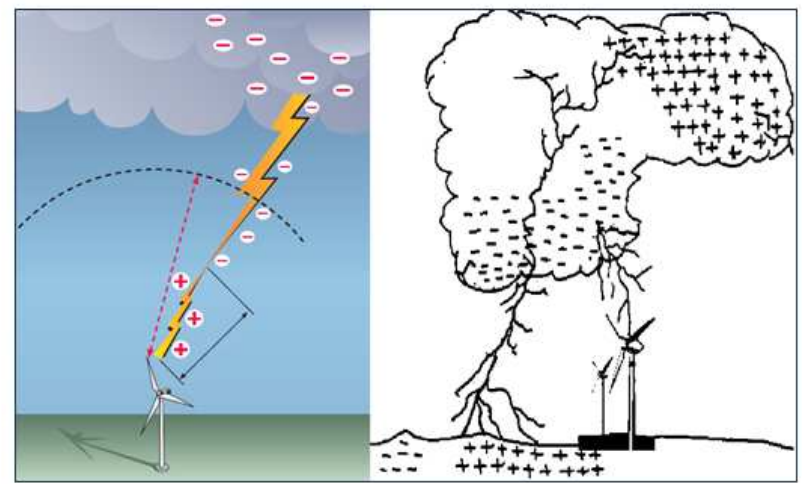

Fig. 1. Development process of lightning and its contact with the wind turbine

\section{LIGHTNING DAMAGE TO WIND TURBINE}

The statistics presented in this study are quoted in IEC/TR 61400-24, highly informative and which present data on the European countries that have known of Events of the turbines damage by lightning strokes (Germany, Sweden and Denmark) where lightning is comparatively infrequent, $4-8 \%$ of all wind turbines will suffer lightning-caused damage every year. However, in areas of greater lightning density, this figure is reported to be considerably higher.

The construction of tall structures for wind power generation or other purposes changes the surrounding environment and can increase the number of lightning strikes. In some countries, damaged number by lightning increased doubled than before. In this way, the increasing installation of wind power generation equipment is causing problems not found in other countries because of the weather conditions.

To better expose the intensity of lightning strikes on wind turbines and the damage will consequently we consider the case of Japan (accordig the International Electrotechnique comission (IEC, 1995) when the lightning on the Sea of Japan side occurs along the coastline all the way from western Hokkaido to the Sanin region. There is lightning on 30 to 40 days per year. This area currently has 46 wind power generation sites, of which 23 have received lightning damage at some time. Of these, 8 have steel towers for lightning protection. Although steel towers can be effective in the event of a lightning strike, lightning rods are not $100 \%$ effective. Depending on the magnitude of the lightning current, mechanical effects in addition to heat effects such as temperature increases in electrical circuits and melting from arcs have been observed.

By simulations indicate that the mechanism in such cases is expansion and contraction from sudden overheating on the discharge path, which causes supersonic pressure waves to spread to the surroundings, generating impact pressure.

Furthermore, unlike summer lightning, winter lightning is not necessarily a momentary current, but instead is sometimes a large current flowing for a certain amount of time with a very large amount of energy. Therefore, the energy from lightning strikes apparently can react with steam on windmill blades (Fig. 2) to cause explosions that damage the equipment. One windmill blade was struck more than 100 times in a single year by winter lightning in Japan. In addition, repair costs over five years for lightning strikes on some windmills equaled the original construction costs. 


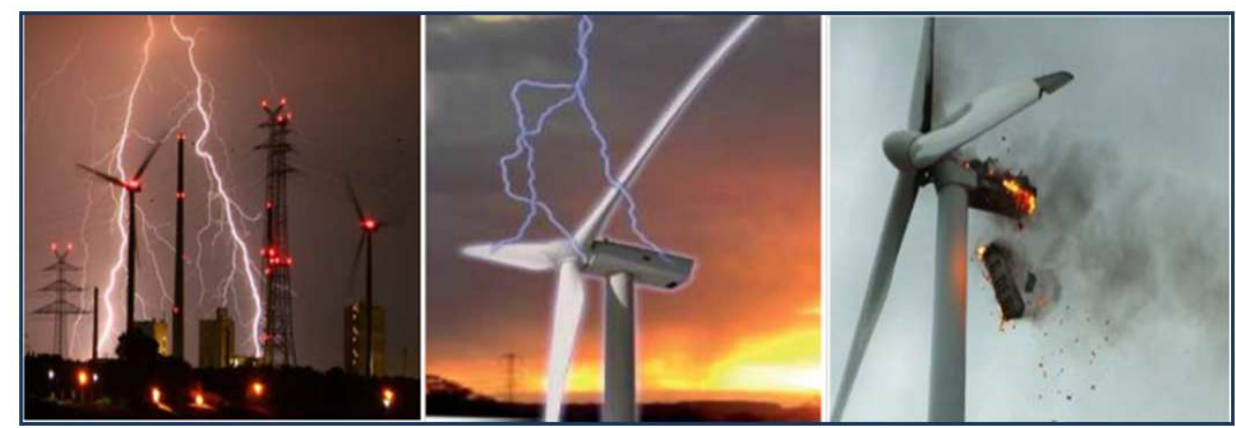

Fig. 2. Wind turbines exposed to lightning strokes

In recent years, windmills have become markedly larger. The height of the blade tips on many of these large windmills is over $100 \mathrm{~m}$, which increases the frequency of damage from lightning strikes. Damage to the blades of large windmills have higher repair costs and require more time for replacement (including transport and installation). The increase in windmill downtime has brought about a decrease in the operation rate and utilized capacity of windmill equipment.

Almost all modern turbine blades are constructed with built-in lightning protection in the form of conducting elements. This improved blade design has significantly reduced the amount of blade damage. Another observation from the report's northern European data is that only one-third of the lightning faults were caused by direct strikes to the turbine (Bermudez et al., 2005). The other two-thirds were attributed to lightning strikes to the power and telecommunication networks connected to the turbines.

\subsection{Principal Lightning Risk Factors}

The above statistics give credence to the main conclusion of a study commissioned by the European Union and conducted by the University of Manchester: "The protection of wind turbine electronic systems from indirect effects is of equal importance to, if not greater than, the protection against direct effects" (Baba and Rakov, 2005).

The three risk factors to be mitigated then are as follows.

\subsection{Damage to Blades Caused by Direct Strikes}

This damage can be caused by strikes to the tips of the blades and also to strikes along the length of the blades. Almost all direct strikes to a wind turbine will hit the rotor blades.

\subsection{Damage Caused by Surge Currents}

This damage can be caused by surge currents originating from either direct strikes to the blades or coming from (indirect) strikes to connected power and data lines. This would include the ac power lines as well as the telephone or supervisory control and data acquisition lines used to remotely control the turbines.

\subsection{Damage Caused by Voltages}

This damage can be caused by voltages induced in circuits (power as well as control) adjacent to the necessary down-conductors that carry the lightning current to "earth."

\subsection{Evaluation of Lightning Incidence to Wind Turbines}

The design of a lightning protection system LPS should be based on the risk of lightning striking the structure in question. This risk is a function of the structure height, the local topography and the local level of lightning activity.

Elevated objects such as wind turbines experience both downward and upward flashes, the proportion being a function of object height (Rachidi et al., 2008). The total annual lightning incidence $N$ (Fig. 8) is given by Equation 1:

$$
N=N_{u}+N_{d}
$$

where, $\mathrm{Nu}$ and $\mathrm{Nd}$ are the annual number of upward flashes and downward flashes, respectively.

Based on observations of the lightning incidence to structures with heights ranging from 20 to $540 \mathrm{~m}$ situated on a flat surface in different regions of the world, Eriksson (Fig. 3) derived the following Equation 2 for $N$ (Rachidi et al., 2008): 
$N=N_{g} \cdot 24 \cdot h_{s}^{2.05} \cdot 10^{-6}$

where, $h s$ is the height of the structure in meters and $\mathrm{Ng}$ is the ground flash density in $\mathrm{km}^{2}$ year ${ }^{-1}$.

The international electrotechnique comity IEC recommends that wind turbines on a flat terrain be modeled as a tall mast with a height equal to the hub height plus one rotor radius, the equivalent attractive or collection area being defined as a circle with a radius of three times the turbine height Equation 3:

$$
R_{a}=3 \cdot h_{s}
$$

Following the (IEC, 2010), the overall number of lightning flashes to the wind turbine (Fig. 3) is calculated using the expression Equation 4:

$$
N=N_{g} \cdot \pi \cdot\left(3 h_{s}\right)^{2} \cdot 10^{-6}
$$

Wind turbine failures due to lightning depend strongly on the terrain where the wind parks are installed. As reported by the (IEC, 1995), wind turbines installed in the low mountain areas in Germany have a higher risk of lightning damage (14 faults per 100 unit years) compared to wind turbines installed in the coastal areas (5.6 faults per 100 unit years). The evaluation of lightning incidence to wind turbines situated in mountainous regions is much more difficult than on flat ground due to the fact that topological factors will play a major role in the enhancement of the electric field at the top of the wind turbine.

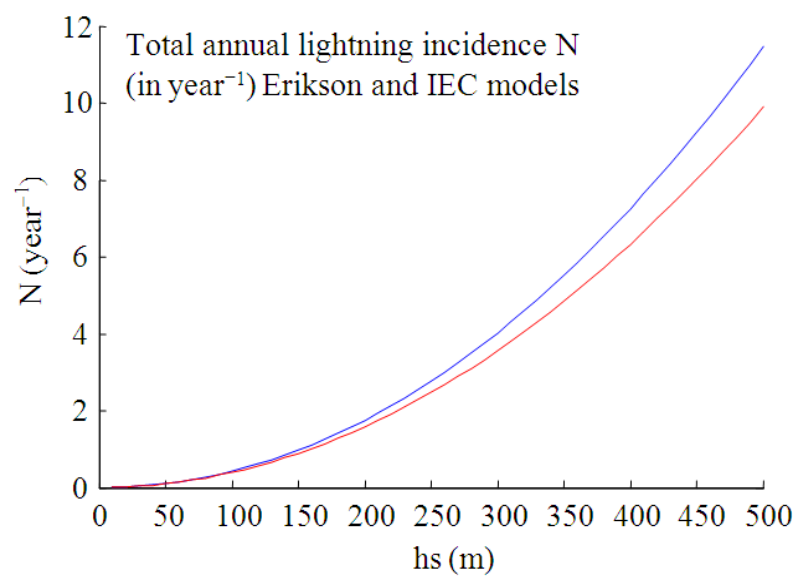

Fig. 3. Total annual lightning incidence $\mathrm{N}$ (in year ${ }^{-1}$ ) according Erikson and IEC model Model

\section{TRANSIENT BEHAVIOR OF LIGHTNING CURRENT IN THE BODY OF THE TURBINE}

When lightning strikes an elevated tower or wind turbine, the transient phenomena in the strike object introduce changes in the original lightning current waveform. The observed current parameters within the structure of the strike object are therefore 'disturbed' by the presence of current reflections and the degree of disturbance depends on the physical and electrical characteristics of the strike object (Bermudez et al., 2005).

The influence of the strike object on the current waveform (Fig. 4) has been recently investigated by a number of research groups around the world and several of the so-called engineering return-stroke models have been extended to take into account the presence of the elevated strike object. In some of these studies, the strike object was modeled as an ideal, uniform transmission line. We can use the models developed for lightning return strokes to static elevated strike objects such as towers to discuss the way in which they should be adapted to the case of wind turbines.

In the return stroke models that take into account the strike structure, it is often assumed that the propagation speed of current pulses along the strike object is equal to the speed of light $\mathrm{c}$ and that the current reflection coefficients at its extremities $\left(\rho_{t}\right.$ at the top and $\rho_{g}$ at the bottom) are constant. Further, the existence of upwardconnecting leaders and any reflections at the return stroke wave front are neglected.

The bottom reflection coefficient for the current in the tower can be expressed in terms of the characteristic impedance of the tower, $Z_{t}$ and the grounding system impedance, $Z_{g}$, as follows Equation 5:

$\rho g=\frac{z_{t}-z_{g}}{z_{t}+z_{g}}$

Similarly, the top reflection coefficient for the current in the tower can be expressed in terms of the characteristic impedance $Z_{t}$ and the equivalent impedance of the lightning return stroke channel $Z_{c h}$ Equation 6:

$\rho_{t}=\frac{z_{t}-z_{c h}}{z_{t}+c h}$ 


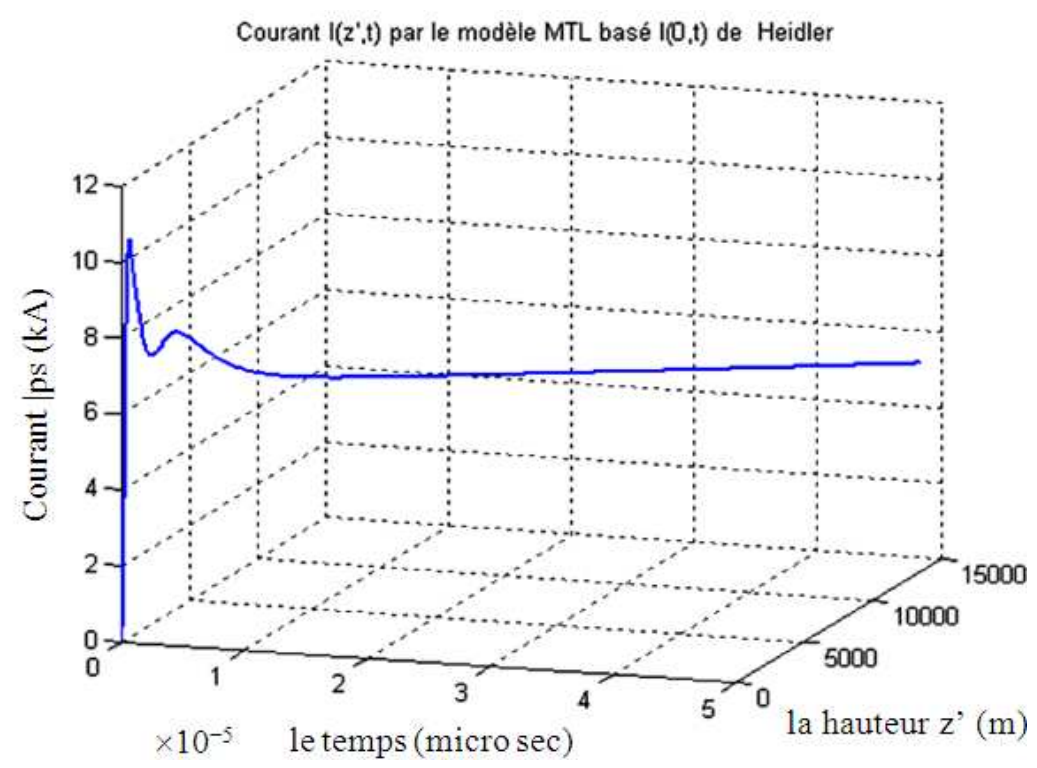

Fig. 4. Lightning current of MTLE model based on Heidler current $I(0, t)$

For a lightning return stroke initiated at the top of the strike object, the current along it and along the lightning channel for a given height $z$ were derived by (Motoyama et al., 1996) and it is given by:

$$
\begin{aligned}
& i(z, t)=\left(1-\rho_{t}\right) \sum_{n=0}^{\infty}\left[\rho_{t}^{n} \cdot \rho_{g}^{n} i_{0}\left(h, t-\frac{h-z}{c}-\frac{2 n h}{c}\right)\right. \\
& . u\left(t-\frac{h-z}{c}-\frac{2 n h}{c}\right)+\rho_{t}^{n} \cdot \rho_{g}^{n+1} i_{0}\left(h, t-\frac{h+z}{c}-\frac{2 n h}{c}\right) \\
& \left.. u\left(t-\frac{h+z}{c}-\frac{2 n h}{c}\right)\right]
\end{aligned}
$$

And for $h<z<H_{t o t}$ :

$$
\begin{aligned}
& i(z, t)=\left[P(z-h) \cdot i_{0}\left(h, t-\frac{z-h}{v^{*}}\right)-\rho_{t} i_{0}\right. \\
& \left(h, t-\frac{z-h}{c}\right)+\left(1-\rho_{t}\right)\left(1+\rho_{t}\right) \sum_{n=0}^{\infty} \rho_{g}^{n+1} \rho_{t}^{n} i_{0} \\
& \left(h, t-\frac{h+z}{c}-\frac{2 n h}{c}\right) \cdot u\left(t-\frac{h+z}{c}-\frac{2 n h}{c}\right) \cdot u\left(t-\frac{z-h}{v}\right)
\end{aligned}
$$

where, io $(h, t)$ is the so-called 'undisturbed' current, defined as the current that would be measured at the top of the strike object (lightning attachment point) if both reflection coefficients $\rho_{t}$ and $\rho_{g}$ were equal to zero, $\mathrm{z}$ is the height along the strike object for Equation 7 and along the channel for Equation 8, $c$ is the speed of light, $v$ is the return stroke speed, Htot is the total height, obtained by adding the lengths of the lightning channel and of the elevated strike object, $v^{*}$ is the current-wave speed in the lightning channel and $u(t)$ is the Heaviside unit step function.

For $0 \leq z \leq h$.

In Table 1 the different return-stroke models are defined as Bruce-Golde (BG) model, Traveling Current Source (TCS) model, Transmission Line (TL) model, MTLL model and MTLE mode 1 (Motoyama et al., 1996).

\subsection{The Modified Transmission Line Model, MTLE}

Established by Nucci, Rachidi (Baba and Rakov, 2005; Dib et al., 2007), the model MTLE (Fig. 5) corrects the defects of the TL model while keeping its simplicity by allowing an easy use in the electromagnetic radiation, based on this formulation of the space-temporal distribution along the channel of the current $i\left(z^{\prime}, t\right)$, defined by Equation 9:

$$
\begin{array}{ll}
i\left(z^{\prime}, t\right)=i\left(0, t-z^{\prime} / v\right) \exp \left(-z^{\prime} / \lambda\right) & z^{\prime} \leq v t \\
i\left(z^{\prime}, t\right)=0 & z^{\prime}>v t
\end{array}
$$

More recently, Heidler proposed a new analytical expression to simulate the current Equation 10:

$i(0, t)=\frac{I_{0}}{\eta} \frac{\left(t / \tau_{1}\right)^{n}}{1+\left(t / \tau_{1}\right)^{n}} \exp \left(-t / \tau_{2}\right)^{n}$ 


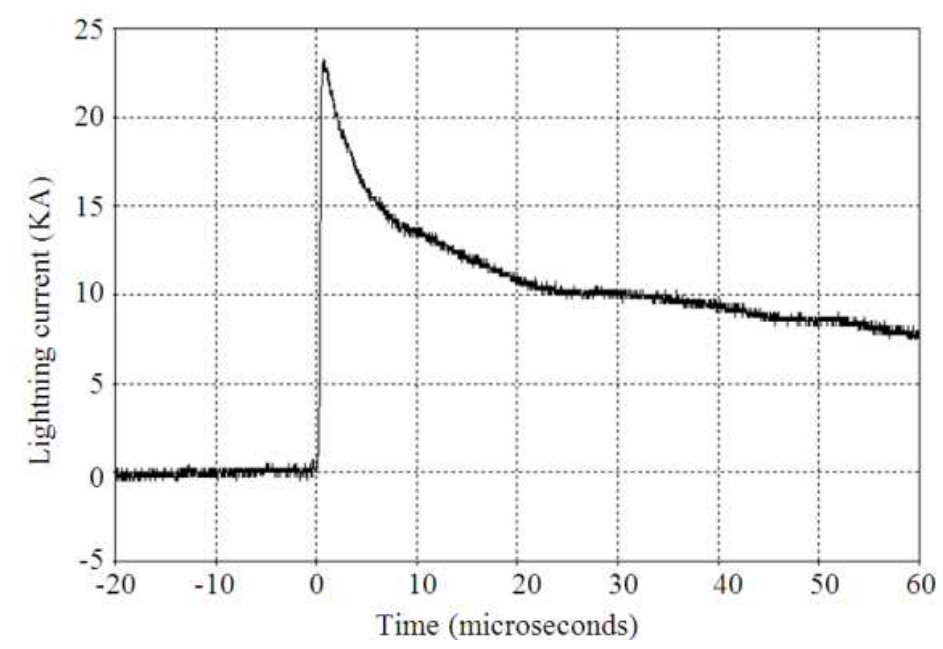

Fig. 5. Experimental current at lightning channel base (Dib et al., 2007)

Table 1. $\mathrm{P}\left(\mathrm{z}^{\prime}\right)$ and $\mathrm{v}^{*}$ for different return stroke models

\begin{tabular}{lll}
\hline Model & $\mathrm{P}\left(\mathrm{z}^{\prime}\right)$ & $\mathrm{v}^{*}$ \\
\hline BG & 1 & $\infty$ \\
TCS & 1 & $-\mathrm{c}$ \\
TL & 1 & $\mathrm{~V}$ \\
MTLL & $1-\mathrm{z}^{\prime} / \mathrm{H}_{\text {tot }}$ & $\mathrm{V}$ \\
MTLE & $\operatorname{Exp}\left(-\mathrm{z}^{\prime} / \lambda\right)$ & $\mathrm{V}$ \\
\hline
\end{tabular}

When:

$$
\eta=\exp \left[-\left(\frac{\tau_{1}}{\left.\tau_{2}\right)}\right)\left(n \frac{\tau_{2}}{\tau_{1}}\right)^{\frac{1}{n}}\right]
$$

$I_{0}=$ The magnitude of the current in the channel base

$\tau l=$ The time-constant of the face

$\tau 2=$ The constant of decrease

$\eta=$ The factor of correction factor of magnitude

$n=$ An exhibitor ranging between 2 and 10

For lightning to wind turbines, the previous model needs to be adapted to take into account the discontinuity between the body and the blades of the wind turbine system at the hub. The value of the discontinuity is a function of a number of electrical and geometrical parameters of the blades, of the hub, of the nacelle and of the base. The instantaneous angle of the struck blade with respect to the base may strongly influence the reflection and transmission coefficients at the discontinuity.

\subsection{Impact of Carbon Reinforced Plastic}

In (Rachidi et al., 2008), Carbon Reinforced Plastic materials are considered as electrical conductors and it is recommended to bond CRP (Fig. 6) to other conducting components for lightning protection purposes. However, this recommendation raises two questions which need to be addressed:

- Are CRP components able to conduct lightning current without being damaged?

- How should the bonding between CRP and LPS be made?

Another issue related to the use of CRP in wind turbine blades is their response to the static electric field below a thundercloud. It is indeed well known that the electric field Eg at ground level below thunderclouds can reach values of about -5 to $-15 \mathrm{kV} / \mathrm{m}$. It is likely that the CRP material in the blade experiences fields which vary (with the rotation of the blade) from $\mathrm{Eg}$ (when the blade tip is near the ground) to a value than can reach a few times Eg, due to the field enhancement effect, when the blade tip is at its highest position. Further testing is needed to evaluate the behavior of CRP materials in the presence of such electric fields.

Another important issue is the mechanical stresses resulting from the energy dissipation in CRP laminates due to the circulation of eddy currents (Fig. 7), which are induced by magnetic field changes produced by lightning currents flowing in other conductive parts within the blade. The circulation of eddy currents results in an energy dissipation as heat, which can generate mechanical stresses. To evaluate the eddy current losses in CRP laminates, we consider the geometry presented in Fig. 7. 
The CRP laminate is defined by a volume of thickness d, width 1 and length $\mathrm{h}$, parallel to and at a distance $\mathrm{R}$ from the lightning down conductor. The average loss due to eddy currents in a laminate is given by Equation 11:

$P(f)=\frac{k(f) d f}{2} B_{\max }(w)^{2} \frac{\sinh (k(f) d)-\sin (k(f) d)}{\cosh (k(f) d)-\cos (k(f) d)}$

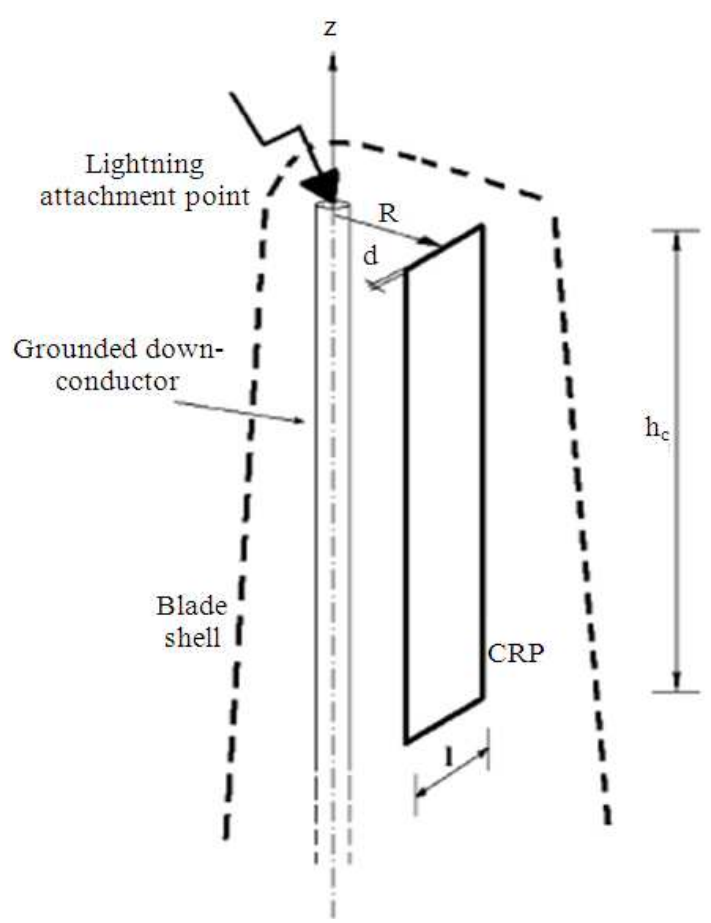

Fig. 6. Geometry for the evaluation of eddy currents in a CRP laminate (Motoyama et al., 1996)

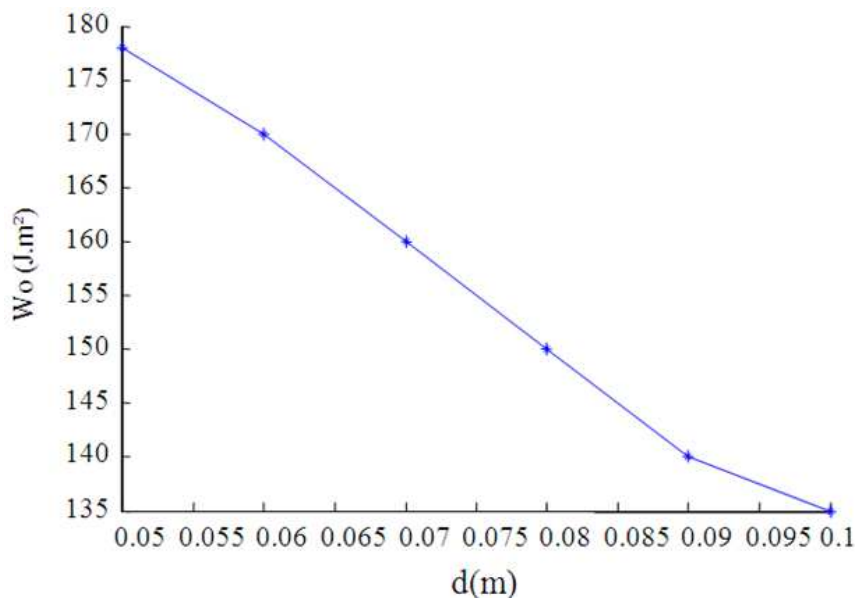

Fig. 7. Specific dissipated energy Wo in a CRP laminate of width d (Motoyama et al., 1996) 


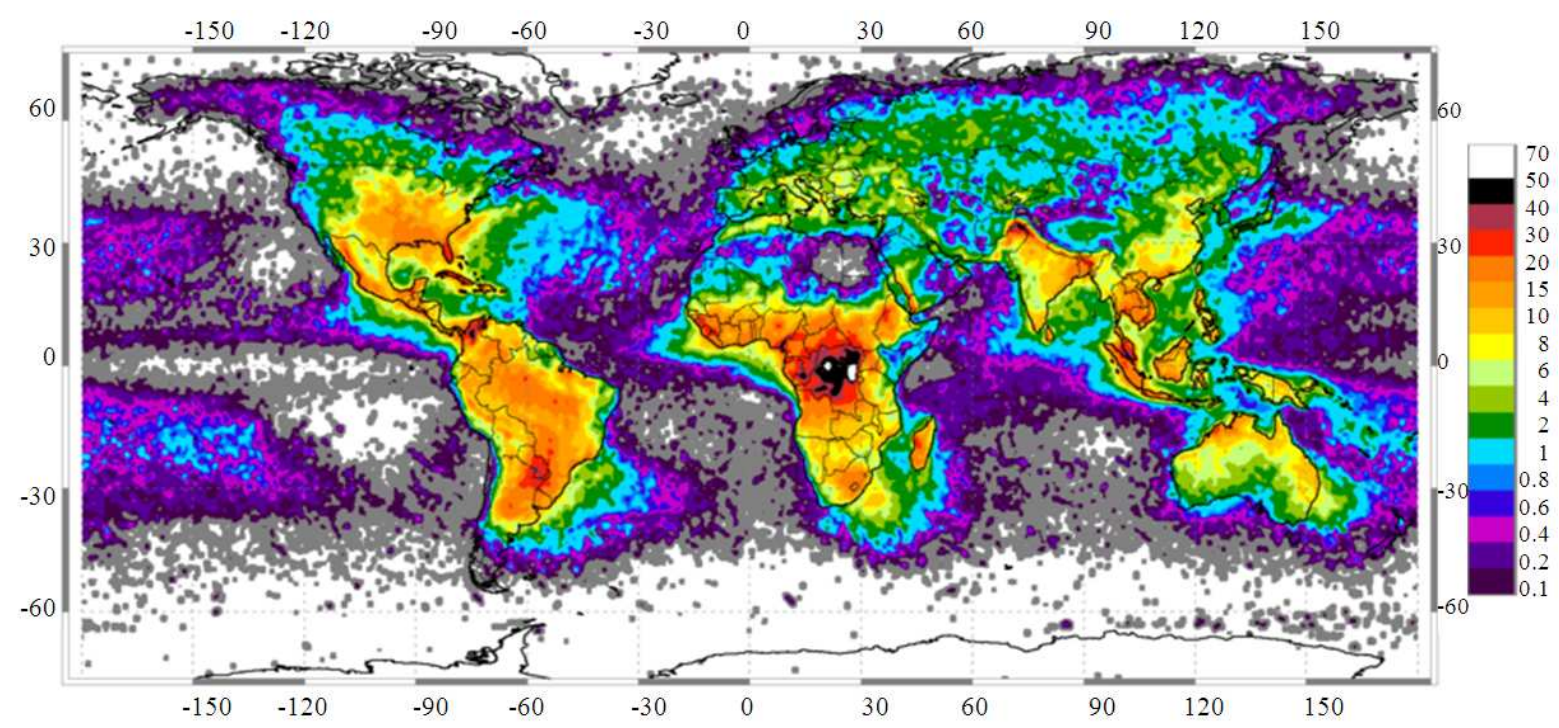

Fig. 8. Global map of lightning incidence $\left(\mathrm{N}^{\circ}\right.$ of strikes $\left./ \mathrm{km}^{2} / \mathrm{yr}\right)$

$L$ is the medium permeability and $r$ is the conductivity of the CRP.

The energy dissipated per unit volume is given by Equation 12:

$W^{\prime}=2 \int_{0}^{f \max } \mid p(f) d f$

And the total dissipated energy in the laminate is therefore Equation 13:

$W=W^{\prime} \cdot I \cdot d \cdot h$

Figure 6 present the specific energy $W o=W /(l . h)$ in $\mathrm{J} / \mathrm{m}^{2}$ as a function of width $\mathrm{d}$ and considering the following parameters used in (Motoyama et al., 1996): R $=0.2 \mathrm{~m}, \sigma=7.2469104 \mathrm{~S} \mathrm{~m}^{-1}$ and $\mu_{\mathrm{r}}=1.0$ The return stroke current corresponds to a typical first return stroke and has an amplitude of $30 \mathrm{kA}$.

\section{CONCLUSION}

In the term of this study we can finish off the following conclusion and recommendations:

- The lightning damage is the single largest cause of unplanned downtime in wind turbines and that downtime is responsible for the loss of countless megawatts of power generation

- Lightning protection of wind turbines presents a number of new challenges due to the geometrical, electrical and mechanical particularities of the turbines. This is especially true for modern units since they are becoming taller and because carbon fiber composite materials are being used to reinforce them. The main conclusions of the chapter are summarized here under

- The risk assessment for the purpose of lightning protection system design is based on empirical formulas for the estimation of the number of flashes to a tall object on a flat terrain. The rotation of the blades may have a considerable influence on the number of strikes to the blades of large wind turbines as these may be triggering their own lightning

- The simulation results show that the influence of the height is important in the frequency of lightning on the Wind turbines where Erikson's model gives more credibility and deserves to be adopted to provide for a more efficient protection system against lightning and the transient phenomena in general

The presence of carbon reinforced plastics in the blades introduces a new set of problems to be dealt with in the design of the turbines' lightning protection system.

\section{REFERENCES}

Arboleda, J.I.B., 2003. Lightning Currents and Electromagnetic Fields Associated With Return Strokes to Elevated Strike Objects. 1st Edn., PhD. Thesis, EPFL. 
Baba, Y. and V.A. Rakov, 2005, Lightning electromagnetic environment in the presence of a tall grounded strike object. J. Geophys. Res. DOI: 10.1029/2004JD005505

Berger, K., 1972. Mesungen und resultate der blitzforschung auf dem Monte San Salvatore bei Lugano. der jahre. Bull. SEV., 63: 1403-1422.

Bermudez, J.L., F. Rachidi and M. Rubinstein, 2005. Far-field-current relationship based on the TL model for lightning return strokes to elevated strike objects. IEEE Trans. EEMC, 47: 146-159 DOI: 10.1109/TEMC.2004.842102

Dib, D., A. Haddoche and F. Chemam, 2007. The returnstroke of lightning current, source of electromagnetic fields (study, analysis and modelling). Am. J. Applied Sci., 4: 42-48. DOI: 10.3844/ajassp.2007.42.48

IEC, 1995. Protection of structures against lightning. Part 1: General principles. Proceedings of the International Electrotechnical Commission (IEC' 65), Geneva, Switzerland.
IEC, 2010. Wind turbine generator systems. Part 24: Lightning protection. Proceedings of the International Electrotechnical Commission, (IEC' 10), Geneva, Switzerland.

Motoyama, H., W. Janischewskyj, A.M. Hussein, R. Rusan and W.A. Chisholm et al., 1996. Electromagnetic field radiation model for lightning strokes to tall structures. IEEE Trans. Power Delivery, 11: 1624-1632. DOI: 10.1109/61.517526

Pavanello, D., F. Rachidi and M. Rubinstein, 2007. On return stroke currents and remote electromagnetic fields associated with lightning strikes to tall structures: 1. Computational models. J. Geophys. Res. DOI: 10.1029/2006JD007958

Rachidi, F., M. Rubinstein and J. Montanya, 2008. A review of current issues in lightning protection of new-generation wind-turbine blades. IEEE Trans. Ind. Electron., 55: 2489-2496. DOI: 10.1109/TIE.2007.896443

\section{APPENDICE}

Table 2. Damaged windmills by component (unit: \%)

\begin{tabular}{lccr}
\hline Damaged component & Denmark & Germany (450 kW and up) & Sweden (450 kW and up) \\
\hline Blade & 10 & 35 & 43 \\
Power system & 20 & 20 & 22 \\
Control system & 51 & 36 & 18 \\
Mechanism & 7 & 4 & 4 \\
Other & 12 & 5 & 13 \\
\hline
\end{tabular}

Table 3. Lightning strike types and phenomena

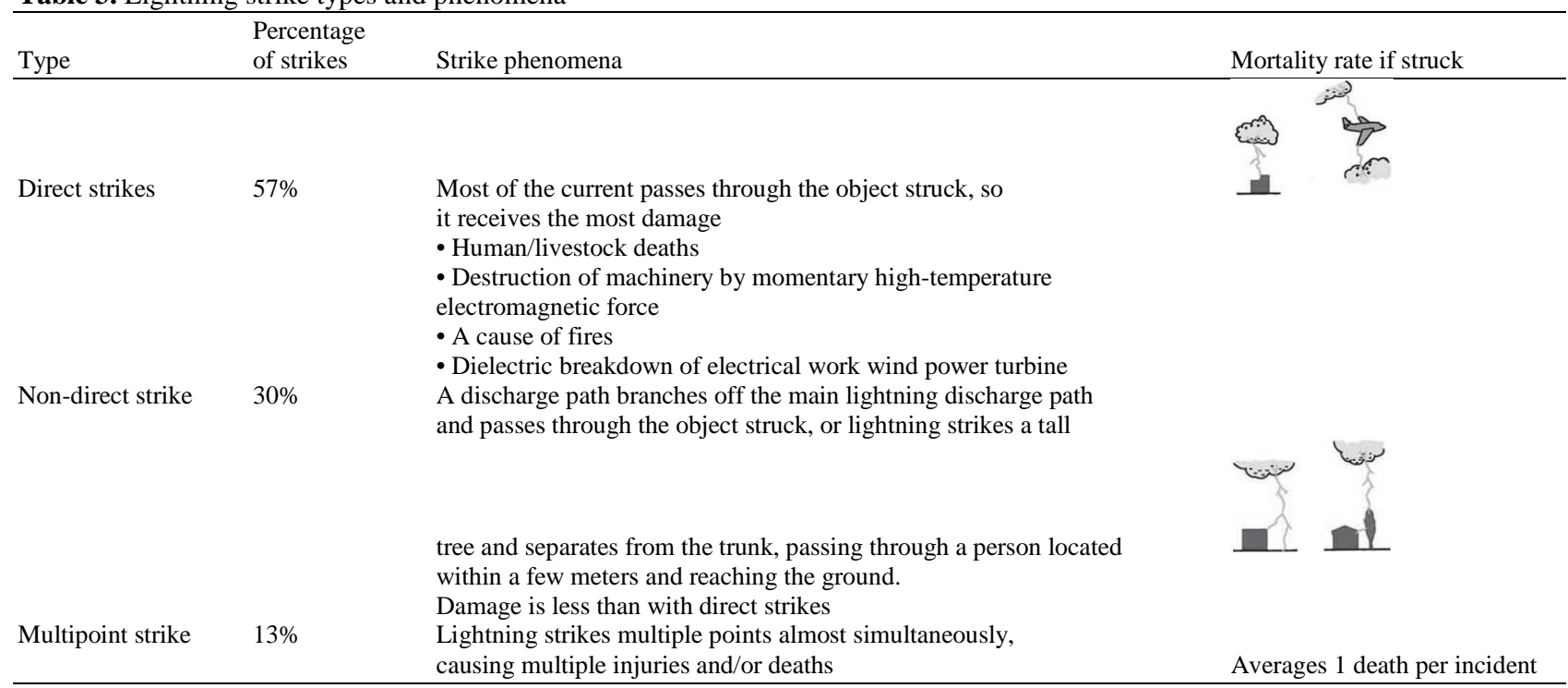

